\title{
REESTRUTURAÇÕES NA ADMINISTRAÇÃO PÚBLICA BRASILEIRA E OS DESDOBRAMÉNTOS NA EDUCAÇÃO SUPERIOR
}

\author{
RESTRUCTURINGS IN THE BRAZILIAN PUBLIC ADMINISTRATION \\ AND THE UNFOLDINGS IN HIGHER EDUCATION
}
RESTRUCTURATIONS DANS L'ADMINISTRATION PUBLIQUE BRÉSILIENNNE ET SES DÉROULEMENTS DANS L'ENSEIGNEMENT SUPÉRIEUR

\section{REESTRUCTURACIONES EN LA ADMINISTRACIÓN PÚBLICA BRASILEÑA Y LOS DESDOBLAMIENTOS EN LA EDUCACIÓN SUPERIOR}

\author{
Raquel Aparecida Souza * \\ Marcelo Soares Pereira Silva **
}

\begin{abstract}
RESUMO
Este artigo apresenta elementos para análise e discussão acerca do processo de reestruturação da administração pública brasileira frente ao movimento reformista desencadeado nos anos 90 do século XX, objetivando situar e compreender os desdobramentos dessas transformaçôes na educação superior. A reflexão se inicia a partir da compreensão de um conjunto de apontamentos e reflexóes sobre o empreendimento de reformas conhecido por gerencialista, de modo a situá-lo no contexto social, econômico e político que o permeou. Ressaltam-se suas propostas e seus objetivos norteadores, baseando-se nos argumentos apresentados por diversos documentos oficiais e perspectivas dos seus idealizadores, e, por fim, propõe-se uma reflexão desse processo reformista e suas implicaçôes para um novo modelo de gestão, também requerido para a educação superior.
\end{abstract}

Palavras-chave: Reforma administrativa. Educação superior. Reforma na educação.

* Mestre em educação pela Universidade Federal de Uberlândia (UFU, 2007). Professora Assistente da Universidade Federal do Tocantins - UFT - Curso de Pedagogia do Campus Universitário de Arraias - TO (eraquelas@gmail.com).

** Doutor em Educação pela Universidade Estadual de Campinas (Unicamp, 1999). Professor Adjunto da Universidade Federal de Uberlândia - UFU - Faculdade de Educação - MG (marcelosoares@ufu.br). 


\section{CONSIDERAÇÕES INICIAIS}

Neste texto analisa-se o processo de reestruturação da administração pública brasileira frente ao movimento reformista desencadeado nos anos de 1990, objetivando situar e compreender os seus desdobramentos na educação superior. Inicia-se com uma compreensão acerca de um conjunto de reflexões e apontamentos sobre esse empreendimento reformista, de modo a situá-lo no contexto social, econômico e político que o permeou.

Em seguida, são apontadas as propostas e os objetivos norteadores da reforma gerencialista, a partir da concepção de documentos governamentais e da perspectiva dos seus idealizadores, e, por fim, propõe-se a discussão desses elementos para a compreensão do processo reformista e suas implicaçōes para um novo modelo de gestão requerido, também, para a educação superior.

Os anos de 1990 configuraram-se como um período de importantes reformas no mundo e no Brasil, sobretudo no período de governo do Presidente Fernando Henrique Cardoso (FHC), em que o marco de suas práticas governamentais se processou a partir de propostas e práticas para a realização de uma significativa mudança na estrutura estatal, identificada por "Reforma Gerencial do Estado".

\section{REESTRUTURAÇÃO NA ADMINISTRAÇÃO PÚBLICA BRASILEIRA}

Durante os governos de FHC (1995-1998 e 1999-2002), o desenvolvimento de reformas em vários setores do Estado encontrou um campo fértil, pois suas práticas de governo eram favoráveis a uma reestruturação na base estatal da administração pública, que era considerada ineficiente para conduzir o desenvolvimento do país.

Desde o início desse governo, verificou-se uma série de açōes desenvolvidas para a consolidação das reformas no Brasil, e suas justificativas estiveram presentes em diferentes momentos, por meio dos discursos presidenciais, em seminários e congressos, além de diversas matérias publicadas em jornais, revistas, dentre outros meios de comunicação.

No ano de 1995, foi criado o Ministério da Administração Federal e Reforma do Estado (Mare), com a atribuição geral de estabelecer as condiçōes necessárias para que o governo federal otimizasse a capacidade de atuação do Estado, com a missão de orientar e instrumentalizar a reforma do aparelho estatal. Dentre os discursos governamentais, destacam-se aqueles que afirmavam que o Estado apresentava problemas de "governança", considerando que a gestão era rígida e ineficiente, e isso impedia a implantação de políticas públicas mais flexíveis.

No documento "Plano Diretor da Reforma do Aparelho do Estado" (PDRAE), essas consideraçôes ficam claras,

O governo brasileiro não carece de "governabilidade", ou seja, de poder para governar, dada sua legitimidade democrática e o apoio com que conta na sociedade civil. Enfrenta, entretanto, 
um problema de governança, na medida em que sua capacidade de implantar as políticas públicas é limitada pela rigidez e ineficiência da máquina administrativa. (BRASIL, PDRAE, 1995, p. 14).

Para a direção do Mare, foi escolhido Luiz Carlos Bresser Pereira ${ }^{1}$, que apresentou as propostas para a reforma administrativa traduzidas no PDRAE, sendo aprovado e assinado pelo Presidente da República em setembro do ano de 1995.

Em 1996, o governo federal organizou um importante seminário, que teve como eixo temático a reforma do Estado e a mudança de paradigmas da administração pública. Esse seminário contou com a participação de conferencistas e intelectuais representantes de diferentes países, como, por exemplo, da Nova Zelândia, dos Estados Unidos, da Inglaterra, entre outros. Teve o apoio de organismos internacionais, como as Organizações das Nações Unidas (ONU), o Centro Latino-Americano de Administração para o Desenvolvimento (Clad) e o Banco Interamericano de Desenvolvimento (BID).

Os textos de referência desse seminário resultaram no livro intitulado Reforma do Estado e Administração Pública Gerencial, organizado por Bresser-Pereira e Peter Spink, que, em boa medida, se constituiu num documento basilar para a divulgação dos princípios reformistas. Os capítulos que o compōem enfocam as justificativas, os diagnósticos, os objetivos, as propostas, enfim, a importância e a necessidade de realização da reforma do Estado e da administração pública, tendo em vista a nova ordem que se colocava no final do século XX e o futuro que se avizinhava.

No discurso de abertura do evento, proferido por FHC, que depois se tornou o texto de abertura do livro citado, percebe-se claramente o anúncio para um novo tipo de Estado, que deveria acompanhar as condiçôes atuais do capitalismo e, assim, ser capaz de enfrentar os novos desafios propostos à sociedade.

No texto, o Presidente da República ressaltava que, somente a partir de uma Reforma, seria possível o Estado brasileiro abandonar as práticas administrativas consideradas arcaicas e ineficientes, conforme suas próprias palavras:

Vivemos hoje num cenário global que traz novos desafios às sociedades e aos Estados nacionais. Não é nenhuma novidade dizer que estamos numa fase de reorganização tanto do sistema econômico, como também do próprio sistema político mundial [...]. É imperativo fazer uma reflexão a um tempo realista e criativa sobre os riscos e as oportunidades do processo de globalização, pois, somente assim, será possível transformar o Estado de tal maneira que ele se adapte às novas demandas do mundo contemporâneo [...]. Reformar o Estado não significa desmantelá-lo [...]. Mudar o Estado significa, antes de tudo, abandonar visões do passado de um Estado assistencialista e paternalista, de um Estado que, por força de circunstâncias, concentrava-se, em larga medida na ação direta para a produção de bens e serviços (CARDOSO, 2001, p. 15).

Como se observa a partir da perspectiva apontada pelo Presidente FHC, uma das justificativas utilizadas para processar a reforma na base da administração pública foi o 
fato de que a administração dominante, do tipo burocrática, mas com nuances de uma administração com elementos patrimonialistas, era considerada inadequada para atender às necessidades e exigências do novo cenário nacional e internacional, político e econômico, frente aos princípios da globalização, das novas tecnologias da produção e da informação e suas implicações nas mudanças do mundo do trabalho. Daí que, para superar a ineficiência e deficiência do Estado, era imprescindível a reforma na sua base administrativa.

No mesmo sentido, o Ministro Bresser-Pereira era enfático ao afirmar que a população deveria lutar para que o Brasil conquistasse uma forma administrativa em superação às tentativas feitas por modelos da gestão patrimonialista e burocrática, pois se acreditava que, mesmo esta última forma tendo surgido para procurar corrigir erros da primeira, ambas ainda coexistiam na gestão pública dos anos de 1990 e se apresentavam como formas de administração que não respondiam mais aos anseios de uma sociedade globalizada e inovadora.

Sobre esses princípios, o Ministro ressaltava que:

A característica que definia o governo nas sociedades pré-capitalistas e pré-democráticas era a privatização do Estado, ou a interpermeabilidade dos patrimônios público e privado. "Patrimonialismo" significa a incapacidade ou a relutância de o príncipe distinguir entre o patrimônio público e seus bens privados. [...] Com o surgimento do capitalismo e da democracia, estabeleceu-se uma distinção entre res pública e bens privados. [...] Foi um grande progresso o surgimento, no século XIX, de uma administração pública burocrática em substituição às formas patrimonialistas de administrar o Estado. [...] Mas era uma estratégia que já não fazia sentido, uma vez que o Estado havia acrescentado às suas funçôes o papel de provedor de educação pública, de saúde pública, de cultura pública (BRESSER-PEREIRA, 2001, p. 26 e 27).

No PDRAE também são destacados vários argumentos usados para justificar as mudanças preconizadas pelo Mare por meio de uma contundente crítica a esses modelos de administração presentes na trajetória e na constituição do Estado liberal moderno.

Afirmava-se, por um lado, que a forma de administração patrimonial mostrava-se como uma administração que era mais vulnerável às práticas de corrupção e de nepotismos. Além disso, o aparelho do Estado funcionava como uma extensão do poder do soberano, e os seus auxiliares e servidores possuíam o status de nobreza real, em que os cargos eram considerados como prebendas. ${ }^{2}$

Por outro lado, as vozes governamentais argumentavam que a administração burocrática, mesmo se contrapondo aos vícios de corrupção e nepotismo da administração patrimonial, também não conseguiu concretizar-se da forma preconizada no modelo ideal. Segundo os documentos e discursos dos defensores da reforma, a administração burocrática: 
[...] surge na segunda metade do século XIX, na época do Estado liberal, como forma de combater a corrupção e o nepotismo patrimonialista. Constituem princípios orientadores do seu desenvolvimento a profissionalização, a idéia de carreira, a hierarquia funcional, a impessoalidade, o formalismo, em síntese, o poder racional-legal. Os controles administrativos visando evitar a corrupção e o nepotismo são sempre a priori (BRASIL, PDRAE, p. 16, 1995).

$\mathrm{Na}$ mesma perspectiva, ressaltava Bresser-Pereira que:

Essa estratégia podia talvez evitar a corrupção e o nepotismo, mas era lenta, cara, ineficiente. Ela fazia sentido no tempo do Estado liberal do século XVIII: um Estado que só precisava de um Parlamento para definir as leis, de um sistema judiciário e policial para fazer cumpri-las, de forças armadas para proteger o país do inimigo externo, e de um Ministro de Finanças para arrecadar imposto (BRESSER-PEREIRA, 2001, p. 26).

O governo entendia que os modelos e as formas de administração com caráter burocrático, com resquícios do modelo patrimonialista, apesar de antigos, ainda se faziam presentes na administração pública do Brasil, e muitas de suas características dificultavam o bom desempenho das atividades econômicas e sociais do país.

Argumentava-se, então, que, para superar essa realidade, o Estado precisava ser redefinido mediante uma administração que prezasse pelo caráter público, mas que, ao mesmo tempo, tivesse um caráter gerencial na busca pela eficiência e eficácia da ação estatal, para a satisfação do interesse público.

\section{ADMINISTRAÇÃO GERENCIAL: UMA NOVA PERSPECTIVA DE GESTÃO PARA O ESTADO}

A “nova forma de administração" pretendida era do tipo gerencial, e sua constituição estaria assentada na própria administração burocrática, de modo que a forma requerida seria uma adaptação e uma melhoria do modelo já existente, eliminando os quesitos que não respondiam ao atual contexto do Estado, como acentuou o Ministro do Mare,

Na verdade, a administração pública gerencial deve ser construída sobre a administração pública burocrática. Não se trata de fazer tábula rasa desta, mas de aproveitar suas conquistas, os aspectos positivos que ela contém, ao mesmo tempo em que vai eliminando o que já não serve (BRESSER-PEREIRA, 2001, p. 264).

A administração gerencial definiu-se, a partir da segunda metade do século XX, como resposta à expansão das funções econômicas e sociais do Estado, ao desenvolvimento tecnológico e à globalização da economia mundial, que, por sua vez, apontava os problemas associados aos modelos das administraçóes anteriores. Isso contribuía, enormemente, segundo o entendimento governamental, para justificar que o país necessitava de um novo modelo de gestão, cujo foco estivesse pautado na qualidade dos 
serviços, na redução de gastos públicos e na cultura do gerenciamento, como fica evidente nos documentos oficiais do governo.

A eficiência da administração pública - a necessidade de reduzir custos e aumentar a qualidade dos serviços, tendo o cidadão como beneficiário - torna-se então essencial. A reforma do aparelho do Estado passa a ser orientada predominantemente pelos valores da eficiência e qualidade na prestação de serviços públicos e pelo desenvolvimento de uma cultura gerencial nas organizações (BRASIL, PDRAE, 1995, p.17).

No documento PDRAE e nos escritos de Bresser-Pereira, destaca-se que os primeiros indícios de uma administração gerencial no Brasil iniciaram-se no governo do Presidente Juscelino Kubitschek, com a criação de comissóes especiais, que objetivaram, dentre outros princípios, a realização de estudos para discutir e alcançar a simplificação dos processos administrativos e desenvolver reformas ministeriais, além da elaboração dos projetos direcionados para reformas globais e descentralização dos serviços.

Outras iniciativas de modernização da administração pública na perspectiva do modelo gerencial são identificadas também nos anos de 1970, com a criação da Secretaria da Modernização (Semor), que buscou implantar novas técnicas de gestão do setor de recursos humanos, e depois, nos anos de 1980, com a criação do Ministério da Desburocratização e o Programa Nacional de Desburocratização (PrND), cujas ações estavam voltadas para o combate à burocratização dos procedimentos e posteriormente tiveram o caráter de contenção dos excessos da expansão da administração descentralizada.

$\mathrm{Na}$ análise presente no Plano Diretor da Reforma, esse processo de desenvolvimento da administração gerencial teria sido interrompido nos anos de 1980, num movimento considerado de "retrocesso burocrático". Isso porque, segundo o documento, a forma como a Constituição Federal de 1988 foi aprovada, bem como o modelo de organização do Estado nela previsto, consistiram em barreiras para o desenvolvimento da gestão gerencialista, como foi sinalizado pelo documento:

A nova Constituição determinou a perda da autonomia do Poder Executivo para tratar da estruturação dos órgãos públicos, instituiu a obrigatoriedade de regime jurídico único para os servidores civis da União, dos Estados-membros e dos Municípios, e retirou da administração indireta a sua flexibilidade operacional, ao atribuir às fundações e autarquias públicas normas de funcionamento idênticas às que regem a administração direta. Esse retrocesso burocrático foi, em parte, uma reação ao clientelismo que dominou o país naqueles anos. Foi também uma conseqüência de uma atitude defensiva da alta burocracia, que, sentindo-se imensamente acusada, decidiu defender-se de forma irracional (BRASIL, PDRAE, 1995, p. 21).

Pelos documentos oficiais da reforma, fica também expresso o sentimento de que a aprovação da Constituição de 1988 não levou em consideração as novas orientações para uma administração pública do tipo gerencial, tendo-se, pois, transformado numa 
"administração arcaica e burocrática ao extremo", como ressalta o próprio Ministro do MARE, ao dizer que a administração tornou-se "altamente centralizada, hierárquica e rígida" (BRESSER-PEREIRA, 2001, p. 246).

A crítica feita pelos reformistas em relação à Constituição Federal de 1988, constituise no sentido de responsabilizá-la pela forte tendência de burocratismo presente na administração pública e por considerar que ela não propunha alternativas para que a gestão pudesse ser realizada de forma a obter um baixo custo operacional e uma alta qualidade nas formas administrativas, e, diante disso, o que se verifica é um processo de mutilação freqüente dos princípios da Constituição em nome de uma chamada "governabilidade".

Dentre as características da administração gerencial, destaca-se que ela seria "orientada para o cidadão e para a obtenção de resultados". Os escritos do Ministro do Mare enfatizam que essa era uma forma de administração que "pressupõe que os políticos e os funcionários públicos são merecedores de grau limitado de confiança e; como estratégia, serve-se da descentralização e do incentivo à criatividade e à inovação; e utiliza o contrato de gestão como instrumento de controle dos gestores públicos" (BRESSER-PEREIRA, 2001, p. 28).

Pimenta (1998), secretário de Logística e Projetos Especiais do Mare, afirma que a reforma teve como princípio fundamental a questão da autonomia, pois, a partir dela, as tendências autoritárias da burocracia desapareceriam. Quanto às características dessa reforma, esse autor destaca que ela teria três dimensões:

[...] a institucional-legal, a cultural e a dimensão-gestão. A dimensão institucional-legal é composta pelas mudanças necessárias no arcabouço normativo e legal da administração pública; a cultural é baseada na mudança de valores burocráticos para gerenciais; e a dimensão-gestão coloca em prática as novas idéias gerenciais e oferece à sociedade um serviço público efetivamente mais barato, mais bem controlado e com a melhor qualidade" (grifos do autor) (PIMENTA, 1998, p. 188).

Sobre essas dimensōes, o Ministro do Mare considerava que a mais difícil de ser implantada era a dimensão referente à gestão, pois, para consolidá-la, teria que se colocar em prática os ideais do gerencialismo e, ao mesmo tempo, oferecer os serviços públicos com melhor qualidade, menor custo e de forma controlada.

Bresser-Pereira, em artigo publicado no ano de 2002, ao fazer um balanço sobre a reforma no Brasil, avaliava que ela conseguiu, por um lado, atingir basicamente os objetivos das três dimensões propostas, sendo, no entanto, mais bem sucedida no que se refere ao plano institucional e cultural do que em relação ao plano da gestão, pois esta era uma dimensão que ainda se encontrava em fase de implementação, por ser de natureza mais lenta, e, assim, demandava tempo. Por outro lado, acentuava que o momento vivido pelo Brasil durante a reforma permitiu que o Estado aprendesse e amadurecesse uma nova forma de pensar a gestão pública. 
[...] começamos todos a mudar nossos conceitos sobre a administração pública, e isso foi muito importante. Uma nova forma de pensar o Aparelho do Estado e sua gestão foi aos poucos surgindo. Foi o conjunto dessas idéias - o modelo de reforma gerencial sua consistência interna e sua capacidade de responder às reais necessidades da administração pública e do país - que garantiram a continuidade e consolidação da reforma (BRESSER-PEREIRA, 2002).

As propostas da reforma da administração pública indicavam o desejo de se alcançar a nova administração com caráter gerencialista, centrada na obtenção dos resultados, no atendimento dos interesses dos cidadãos e na focalização do incentivo à criatividade e à inovação. Para tanto, na perspectiva dos gestores do Estado brasileiro, tais propostas, para alcançarem êxito, deveriam ser desenvolvidas por meio de um tipo especial de contrato de gestão, que se pautava, sobretudo, nos princípios da flexibilização e da descentralização.

Os objetivos da reforma foram associados aos diagnósticos realizados pelo Mare, que, de uma maneira geral, pretendiam, em curto prazo, facilitar o ajuste fiscal, em especial, dos Estados e Municípios e, em médio prazo, tornar cada vez mais eficiente e moderna a administração pública.

Sobre os objetivos da reforma, Bresser-Pereira indicava como seria realizado esse ajuste fiscal e como seria modernizada a administração pública.

O ajuste fiscal será realizado principalmente através da exoneração de funcionários, por excesso de quadros; da definição clara do teto remuneratório dos servidores e da modificação do sistema de aposentadorias, aumentando o tempo de serviço exigido e a idade mínima para aposentadoria, exigindo-se tempo mínimo de exercício no serviço público e tornando o valor da aposentadoria proporcional à contribuição. ... Já a modernização ou o aumento da eficiência da administração pública resultará, a médio prazo, de um complexo projeto de reforma, através do qual se buscará a um só tempo fortalecer a administração pública direta (BRESSER-PEREIRA, 2001, p. 258).

As propostas para a reforma, consolidadas pelo Mare no Plano Diretor da Reforma do Aparelho do Estado, consideravam a existência de quatro setores presentes no aparelho do Estado, sendo eles: 1) Núcleo Estratégico; 2) Atividades Exclusivas do Estado; 3) Produção de Bens e Serviços para o Mercado e 4) Serviços Não-exclusivos ou Competitivos. Consideravam ainda, que, para cada um desses setores, existiria um tipo de propriedade e um tipo de administração específica.

O Núcleo Estratégico seria o setor responsável pela formulação das leis, das políticas públicas, e zelaria pelo cumprimento destas. No caso de um sistema ser federal, seria formado pelo presidente da República, pelos Ministros de Estado, pelos Tribunais Federais e Ministérios Públicos. Também integraria este setor os governadores e seus secretários e a alta administração pública estadual. Além dos instrumentos tradicionais, como a aprovação de leis no Congresso e outros, seria utilizado um tipo especial de contrato de 
gestã $0,^{3}$ o qual permitiria que esse núcleo definisse os objetivos das entidades executoras do Estado, bem como seus respectivos indicadores de desempenho, garantindo-lhes os meios humanos, materiais e financeiros para sua consecução.

Desse modo, o tipo de gestão mais adequado seria uma gestão mista entre a administração pública burocrática e a pública gerencial, pois, segundo afirmava o Plano Diretor da Reforma, nesse setor "o princípio fundamental é o da efetividade entendida como capacidade de ver obedecidas e implementadas com segurança as decisões tomadas" (BRASIL, PDRAE, p. 43). No que se refere à forma de propriedade, o tipo mais apropriado para esse setor seria a forma estatal.

O setor das Atividades Exclusivas do Estado envolveria o poder do Estado, o qual teria a responsabilidade de garantir que as leis e as políticas públicas fossem cumpridas e financiadas. Seria formado pela polícia, pelas Forças Armadas, pelos órgãos de fiscalização e de regulamentação, entre outros. Este setor se identificaria com as agências autônomas, as quais contariam com a presença de uma administração descentralizada, pois haveria a divisão das tarefas entre a sociedade civil e o Estado.

O tipo de gestão para esse setor seria de caráter gerencial, tendo em vista que seu princípio maior era o da busca pela eficiência, ou seja, a busca pela qualidade dos serviços prestados, porém ressalta-se que a forma de propriedade para as atividades exclusivas seria estatal, pois o poder extroverso seria exercido pelo Estado.

O setor de Produção de Bens e Serviços corresponderia à área de atuação das empresas, sendo um setor em que a produção poderia ser realizada pelo setor privado. Neste sentido, os programas de privatização ganhariam grande importância, porque, de acordo com o Ministro Bresser Pereira, as empresas seriam mais eficientes se fossem controladas pelo mercado e administradas pelas entidades privadas, ou seja, controladas pelo princípio da troca, e se caracterizariam pelas atividades econômicas voltadas para o lucro.

Esse setor se distinguiria pela qualidade dos serviços prestados e, para tanto, a forma de gestão deveria obedecer aos princípios gerencialistas, e, assim, o requisito básico também seria o da eficiência, para o qual o tipo de propriedade mais adequado seria a privada, e a propriedade estatal se justificaria somente quando não existissem os capitais privados.

Por fim, o setor dos Serviços Não-Exclusivos seria aquele provido não só pelo Estado, mas também pelo setor privado ou por organizações públicas não-estatais e privadas. Nele, estariam presentes os serviços que envolveriam os direitos humanos fundamentais, como, por exemplo, os serviços da área da educação, da saúde, da cultura e de pesquisa científica. A forma de gestão adequada para esse setor seria também do tipo gerencial, pois tinha como princípio fundamental a busca da eficiência nos serviços prestados.

Para os defensores dessas propostas, a compreensão das concepçōes sobre a forma de propriedade desse setor passaria, primeiramente, pelo entendimento da existência de três 
formas de propriedades permitidas e necessárias no capitalismo contemporâneo, que seriam a propriedade estatal, a propriedade privada e também a propriedade pública não-estatal.

Nas análises do Ministro do Mare, ficava evidenciado o entendimento de que os indivíduos e a sociedade em geral faziam certa confusão em torno da divisão dos direitos de propriedades. Para ele, essa confusão decorria do fato de a sociedade restringir como propriedades de caráter público apenas aquelas pertencentes ao Estado, não admitindo outras formas ou possibilidades de propriedade.

O Ministro entendia que a sociedade precisava compreender que se fazia necessária a implantação de uma nova forma de propriedade, intermediária entre as outras duas, ou seja, a propriedade pública não-estatal, ou ainda, mais bem caracterizada pelas "organizaçôes sociais". Essas organizações sociais teriam como objetivo permitir a descentralização de atividades no setor de prestação de serviços não-exclusivos, nos quais não existiria o exercício do poder de Estado, partindo do pressuposto de que esses serviços seriam mais eficientemente realizados se, mantendo o financiamento do Estado, fossem realizados pelo setor público não-estatal (BRASIL, PDRAE, p. 60).

Nesse sentido, Bresser-Pereira (2001) considerava que:

No capitalismo contemporâneo, as formas de propriedades relevantes não são apenas duas, como geralmente se pensa e como a divisão clássica do direito público e privado sugere ... e sim três: a) a propriedade privada, voltada para a realização do lucro (empresa) ou de consumo privado (famílias); b) a propriedade pública estatal; e c) a propriedade pública-não estatal. Com isso, estou afirmando que o público não se confunde com o estatal. O espaço público é mais amplo que o estatal, já que se pode ser estatal ou não-estatal. No plano do dever ser estatal é sempre público, mas, na prática, não é ... pública a propriedade que é de todos e para todos. É estatal a instituição que detém o poder de legislar e tributar. É estatal a propriedade que integra o aparelho do Estado sendo regida pelo direito administrativo. É privada a propriedade que se volta para o lucro ou para o consumo dos indivíduos ou dos grupos ... a propriedade pública se subdivide em estatal e não-estatal, ao invés de se confundir com estatal; ... as instituiçōes de direito privado voltadas para o interesse público e não para o consumo privado não são privadas, e sim públicas não-estatais (p. 261-262).

No setor dos serviços não-exclusivos do Estado, as atividades dedicadas à educação, como as escolas técnicas, as universidades, os centros de pesquisa, ou o setor da saúde, no que refere aos hospitais e centros de atendimentos médicos, ou mesmo as que se referem à cultura, como os museus e outros, deveriam ser transformadas, segundo os defensores da reforma, no tipo especial de entidade pública não-estatal, ou organizações sociais, pois entendiam que elas facilitariam a parceria entre o Estado e a sociedade.

Para isso, esses serviços deveriam passar por um Programa Nacional de Publicização (PNP), ${ }^{4}$ para consolidarem as organizaçóes sociais, o que seria garantido por meio da Lei 
$\mathrm{n}^{\circ}$. 9.637, de 15 de maio de 1998, que, conforme seu artigo 20, dispunha sobre a qualificação de entidades como organizaçóes sociais, a criação do Programa Nacional de Publicização e dava outras providências.

Em relação aos seus princípios, destaca-se da referida Lei que esse Programa buscava absorver as atividades desenvolvidas por entidades ou órgãos públicos da União e que atuassem nas atividades relacionadas com o ensino, a pesquisa científica, o desenvolvimento tecnológico, a preservação do meio ambiente, a cultura e a saúde.

As entidades que obtenham a qualidade de organizações sociais gozarão de maior autonomia administrativa, e, em compensação, seus dirigentes terão maior responsabilidade pelo seu destino. Por outro lado, busca-se através das organizações sociais uma maior participação social, na medida em que elas são objeto de um controle direito da sociedade através de seus conselhos de administração recrutados no nível da comunidade à qual a organização serve. Adicionalmente se busca uma maior parceria com a sociedade, que deverá financiar uma parte menor, mas significativa dos custos dos serviços prestados (BRASIL, PDRAE, p. 60).

Para esses fins, as transformações deveriam observar as seguintes diretrizes: "I - ênfase no atendimento do cidadão-cliente; II - ênfase nos resultados, qualitativos e quantitativos nos prazos pactuados; III - Controle das açōes de forma transparente" (LEI n ${ }^{\circ}$. 9.637, 1998). Esses aspectos, por sua vez, buscavam consolidar os princípios do modelo de gestão gerencial pela via no Estado brasileiro.

A compreensão desses elementos da reforma foi sintetizada em um diagrama utilizado pelo PDRAE, indicando as formas de propriedade e de administração e sua relação com os setores presentes no aparelho do Estado:

\begin{tabular}{|l|l|l|l|l|l|}
\hline \multirow{2}{*}{$\begin{array}{l}\text { Itens } \\
\text { Polarizados }\end{array}$} & \multicolumn{2}{|c|}{ Forma de Propriedade } & \multicolumn{2}{c|}{$\begin{array}{c}\text { Forma de } \\
\text { Administração }\end{array}$} \\
\cline { 2 - 6 } & Estatal & $\begin{array}{c}\text { Pública } \\
\text { Não Estatal }\end{array}$ & Privada & Burocrática & Gerencial \\
\hline $\begin{array}{l}\text { Núcleo Estratégico } \\
\text { Legislativo, Judiciário, Presidência, } \\
\text { Cúpula dos Ministérios, Ministério Público }\end{array}$ & & & & & \\
\hline $\begin{array}{l}\text { Atividades Exclusivas } \\
\text { Regulamentação, Fiscalização, Fomento, } \\
\text { Segurança Pública, Seguridade Social Básica }\end{array}$ & & & & & \\
\hline $\begin{array}{l}\text { Serviços Não-Exclusivos } \\
\text { Universidades, Hospitais, Centros de } \\
\text { Pesquisa, Museus }\end{array}$ & Publicização & & & & \\
\cline { 2 - 7 } & & & & & \\
\hline $\begin{array}{l}\text { Produção para o Mercado } \\
\text { Empresas Estatais }\end{array}$ & & Privatização & & & \\
\cline { 2 - 7 } & & & & & \\
\hline
\end{tabular}


Nesse contexto, também se fortalecem os ideais da privatização, entendida como uma alternativa para que as instituiçôes sociais, ao serem transformadas nas organizações sociais, pudessem gerar receitas. Assim, para Bresser-Pereira (2001), "a privatização é uma alternativa adequada quando a instituição pode gerar todas as receitas da venda de seus produtos e serviços e o mercado tem condições de assumir a coordenação de suas atividades" (p. 262).

Esses pressupostos de caráter ideológicos da reforma buscavam alocar os direitos sociais, das áreas mencionadas, como da saúde, da educação e da cultura, para o setor dos serviços não-exclusivos do Estado, e seriam definidos pelos princípios do mercado. Com isso, a reforma promoveria a ampliação do espaço privado e a conseqüente diminuição do espaço público, no que se refere aos direitos democráticos, e, ao mesmo tempo, fortaleceria o reconhecimento de um espaço que antes não pertencia necessariamente ao Estado, ou seja, o espaço das organizações sociais.

\section{DESDOBRAMENTOS DA REFORMA GERENCIAL NA EDUCAÇÃO SUPERIOR}

No Brasil, as justificativas utilizadas para executar as reformas na educação superior, nos anos de 1990 estiveram associadas aos principais ideais da reforma administrativa do Estado brasileiro, cuja matriz orientadora foi marcada pela influência das políticas neoliberais patrocinadas pelos organismos multilaterais, conforme anunciado.

Pautados nessas diretrizes, os governos gerenciais entendiam que a saída para as crises existentes no sistema educacional seria a prática das reformas, pois, após a realização de vários diagnósticos efetuados pelo Banco Mundial, foram apontadas crises de gerenciamento motivadas pela má administração do Estado com relação ao sistema educacional e, portanto, compreendiam que as formas de administração predominantes não respondiam às necessidades da nova conjuntura política e social e, com isso, não eram mais capazes de garantir um padrão de qualidade e de eficiência.

Algumas medidas apontadas pelos organismos multilaterais são identificadas e consolidadas nas açôes do presidente FHC, por meio da implementação de uma série de reestruturações e reconfigurações na educação superior, as quais se basearam na lógica do mercado.

Em estudos realizados por Oliveira e Catani (2002), esses princípios que envolveram a reconfiguração na educação superior são claros ao afirmarem que esses elementos envolvem "um novo padrão de modernização e de gerenciamento para o campo universitário, inclusos no atual paradigma de produção capitalista e na reforma da administração pública do Estado" (2000, p. 105). Destacam ainda que até o conceito de universidade foi colocado em discussão, gerando conflitos de identidade, além das questôes como a natureza e a relevância social das instituições públicas. 
Contudo, a reforma na educação superior nos governos de FHC pode ser considerada uma de forma fragmentária, uma vez que foi realizada por meio de uma série de documentos legais, como leis, decretos, portarias, resoluçōes, pareces, entre outros mecanismos. Não houve um documento oficial único que refletisse uma reforma na educação superior, mas, sim, uma série de textos legais, projetos e programas.

Para Mancebo (1998), essa reforma pode ser analisada com base em cinco grandes princípios, que ela identifica por racionalização de recursos, gestão direcionada aos resultados, flexibilização de gestão, qualidade do serviço educacional e descentralização. Cury (1998), de sua parte, avalia que a reforma estaria estruturada em torno de dois eixos: a avaliação e a autonomia.

Oliveira e Catani (2002) analisam as propostas da reforma a partir dos elementos da diversificação e da diferenciação institucional. Shiroma (2004), baseando-se em documentos do MEC, refere que a reforma apresentou três objetivos: a avaliação, a autonomia e a melhoria do ensino.

$\mathrm{Na}$ verdade, esses olhares sobre a reforma da educação superior no Brasil, no final do século XX, evidenciam alguns pilares fundamentais que davam sustentação a ela ao mesmo tempo em que sinalizam elementos de uma gestão gerencial, voltada para a busca dos resultados por meio da competitividade, em resposta aos anseios da lógica empresarial, do mercado e de seus clientes. Como explicam Oliveira e Catani (2002):

A lógica e as ações que presidem a desorganização da educação superior ocorrem na direção de tornar o trabalho acadêmico mais produtivo do ponto de vista dos interesses prevalecentes no mercado. Esta racionalidade econômica revela que a universidade e o trabalho acadêmico só possuem relevância econômica e social quando formam profissionais aptos às necessidades atuais do mercado de trabalho e quando pesquisam, geram ou potencializam os conhecimentos, as técnicas e os instrumentos de produção e serviços que possibilitam a ampliação do capital (p. 24).

Mancebo (1998) também complementa essa idéia ao declarar que:

Este modelo gerencial apresenta por referência básica o atendimento à lógica empresarial e ao mercado competitivo, adotando concepções instrumentais/funcionais de autonomia e de participação. O setor privado, através de dispositivos variados, constitui-se numa fonte de inspiração privilegiada e, nas suas versões mais puras, a fórmula apregoada para sua superação da crise de legitimidade aparece associando-a "a uma imagem de moderna estação de serviços, funcionalmente adaptada às exigências do mercado dos seus clientes e consumidores (Lima, 1997)" (MANCEBO, 1998, p. 1).

Pelo exposto, tem-se que os princípios e as diretrizes da reforma na educação superior, no período em análise, são marcados por elementos da publicização e da descentralização; da diversificação e da diferenciação institucional e da flexibilização (OLIVEIRA; 
CATANI, 2000, 2002; SGUISSARDI, 1999, 2001; MANCEBO, 1998; SILVA JÚNIOR, 2001, 2002).

As políticas para a educação superior, preconizadas nos anos de 1990, impactaram os processos e práticas gestoriais, especialmente nas universidades públicas, as quais tiveram que apresentar alternativas de sobrevivência no contexto da lógica mercadológica. Como exemplo, tem-se o processo de publicização, que correspondeu à tentativa de transformação das instituiçôes de ensino superior em organizações sociais, conforme previsto pela reforma da administração pública, mas que não logrou resultado pleno.

Os pressupostos da reforma administrativa indicavam que todas as instituições que contemplassem os serviços sociais deveriam passar pelo programa de publicização as universidades, fazendo parte do setor definido como de Serviços Não-Exclusivos do Estado, também deveriam acompanhar esse processo e, posteriormente, serem transformadas nas organizações sociais, ou seja, nas instituiçôes de direito privado sem fins lucrativos, como esclarece Silva Júnior (2002), ao afirmar que:

[...] a educação em geral e, em particular, a educação superior foi reconfigurada com muita intensidade pela própria reforma do Estado, na qual está presente a transformação das instituições de educação superior em organizações sociais, que seriam fundações públicas regidas pelo direito privado, retirando com isso a unidade do sistema federal, submetendo esse nível de ensino às regras do privado e subordinando as práticas sociais de docência, pesquisa e extensão ou outro tipo de práticas à racionalidade mercantil (p. 49).

Esses pressupostos representaram uma contradição para a educação superior, pois, como analisa Chauí (1999), a universidade, desde o seu surgimento, foi instituída e almejada para ser uma instituição social, de caráter público, gratuito e que aspirasse às práticas sociais, e não para responder a uma lógica voltada para o mercado.

Para a autora, é necessário considerar as grandes diferenças entre uma universidade ser uma instituição social ou uma organização social. Na primeira forma, ela tem um caráter mais humano e de respeito aos limites da sociedade e aos "princípios naturais da aprendizagem”, enquanto que, na segunda forma, há uma excessiva preocupação com as questôes referentes à produção, à competitividade e à avaliação.

Nesse sentido, Chauí (1999), ao apresentar essas distinções, mostra que uma universidade, quando se enquadra nos princípios de uma organização social, pode ser entendida como uma universidade operacional que por sua vez é:

Regida por contratos de gestão, avaliada por índices de produtividade, calculada para ser flexível, a universidade operacional está estruturada por estratégia e programas de eficácia organizacional e, portanto, pela particularidade e instabilidade dos meios e dos objetivos. Definida e estruturada por normas e padrōes inteiramente alheios ao conhecimento e à formação intelectual, está pulverizada em micro-organizaçōes que ocupam seus docentes e curvam seus estudantes a exigências exteriores ao trabalho intelectual (CHAUÍ, 1999, p. 220-221). 
Retomando o aspecto da publicização, Lordêlo (2001), ao analisar seus efeitos e suas características, assegura que ela é a via mais radical da forma de descentralização proposta pela reforma do Estado, pois ela transfere o que é de competência da esfera pública estatal para a esfera pública não-estatal. Assim,

Com a publicização o Estado permanece com a responsabilidade do provimento e da gratuidade do serviço para o cidadão, mas a gestão é transferida para organizaçôes sociais, entidades sem fins lucrativos e com finalidades públicas. [...] Para dar conta deste novo fenômeno - a publicização, a descentralização é então concebida como todo o processo que envolve tanto a assunção como a transferência de competências da esfera pública estatal para a pública não-estatal, ou seja, da esfera do Estado para a sociedade civil organizada (LORDÊLO, 2001, p. 177).

Nesse sentido, o autor ressalta que a expressão descentralização, na literatura clássica, denota "o ato e o fato da delegação, outorga ou transferência de funções e poderes do nível Federal para os Estados e destes para os Municípios”, apresentando uma série de significados para o termo descentralização, como: municipalização, desconcentração, policentração, redescentralização, nuclearização, privatização, desestatização.

Outra marca na implementação da reforma na educação superior, no período de FHC, refere-se a ênfase dada nas políticas de diferenciação e diversificação institucional. No que se refere à primeira, o esforço empreendido pelos governantes e gestores foi no sentido de reforçar a idéia de que o modelo único de universidade, que tinha como princípio a indissociabilidade entre o ensino-pesquisa-extensão, estava esgotado.

Dentre os vários documentos legais que conduziram a uma maior diferenciação institucional, ressalta-se a Lei de Diretrizes e Bases da Educação Nacional (LDB) no 9.394/96, que, no capítulo sobre educação superior, artigo 54, prevê que "as universidades mantidas pelo Poder Público gozarão, na forma da lei, de estatuto jurídico especial para atender às peculiaridades de sua estrutura, organização e financiamento...”. (BRASIL, LDB 9.394/96, 1996).

A LDB também abriu possibilidades de maior diferenciação interna nas próprias universidades, por meio de diferentes mecanismos de financiamento e parcerias de empresas públicas e privadas. Esses mecanismos pressionaram as universidades a buscar fontes alternativas de receitas para seu custeio e manutenção.

Esse caminho, na verdade, já era apontado pelo Banco Mundial (1995) nas proposições do documento La enseñanza superior: las lecciones derivadas de la experiencia, ao referenciar a necessidade de promover mais incentivos para que as instituiçōes pudessem diversificar suas formas e fontes de financiamento.

Outras medidas, decretos e pareceres foram produzidos para dar sustentação ao que a LDB sugeriu como "estatuto jurídico especial", como o Decreto no 2.207/97, que 
estabeleceu distinções para o ensino superior brasileiro no que se refere ao setor público e privado, permitindo a existência das Instituições de Educação Superior (IES) de caráter público, as de caráter privado sem fins lucrativos e as privadas com fins lucrativos.

Esse Decreto, revogado pelo de ${ }^{\circ}$ 2.306/97, estabeleceu, quanto à organização acadêmica das instituiçōes de ensino superior do sistema federal, segundo seu artigo $8^{\circ}$, que elas se classificariam em universidades, centros universitários, faculdades integradas, faculdades e institutos superiores ou escolas superiores.

Esse movimento se associava também ao ideário da flexibilização proposta pela reforma, que visava obter maior diferenciação institucional por meio da diversificação de ofertas de cursos e vagas. Nesse propósito, o governo brasileiro apontava que o modelo de educação superior estava esgotado e, como alternativa, propunha um sistema baseado na flexibilidade e na diversidade no que refere aos currículos, à gestão, à avaliação e à estrutura das instituições públicas.

Para Mancebo (1998), esse modelo articula-se ao princípio da "flexibilidade de gestão". Para o autor,

Em nome da flexibilização, está postuladas a eliminação do regime jurídico único e da dedicação exclusiva para o exercício da docência, favorecendo contratos mais ágeis e econômicos, como os "temporários", "precários" e outras denominaçōes já em vigor. A reformulação curricular em vigor é outro exemplo preocupante de flexibilização dos cursos superiores, pois, a permanecerem as motivaçoes do MEC e de algumas "comissões de especialistas" aí instituídas, as tendências apontam para um aligeiramento da duração e baixa da qualidade dos conteúdos fornecidos nos diversos cursos de formação, deixando-se, possivelmente, o aprofundamento de caráter profissionalizante para o nível seguinte - a pós-graduação (MANCEBO, 1998, p. 2).

No caso da educação superior, entre outros elementos, a idéia era ampliar o sistema educacional de forma a gastar o menos possível e assim fortalecer o ideário que norteava essas mudanças e que implicava o fim do regime jurídico único das universidades públicas e a contratação direta de funcionários com base em sua capacidade profissional.

\section{CONSIDERAÇÕES FINAIS}

Com efeito, o modelo gerencialista norteador da reforma da administração pública no Brasil influenciou diretamente a reforma da educação superior dos anos de 1990, cujo objetivo central visava ao crescimento da produtividade, da eficiência e da eficácia do sistema, e, por sua vez, os processos e práticas gestoriais tiveram que acompanhar essa tendência.

No Brasil, a reformulação administrativo-gerencial do Estado, nos anos 90 do século $\mathrm{XX}$, configurou-se como um importante instrumento de difusão das mudanças e 
transformações requeridas pela concepção empresarial e mercadológica, realizada por meio das reformas desenvolvidas em vários setores sociais, e nesse sentido, consolidando a redefinição do papel do Estado brasileiro para o tipo de um Estado Gerencial.

Esse modelo de gerenciamento, disseminado no contexto empresarial, foi marcante nas propostas reformistas, pois, pelos anseios governamentais, acreditava-se que seria um modelo que permitiria que o sistema público funcionasse com mais eficácia e eficiência. Nessas circunstâncias, o modelo de gestão pública que vai sendo preconizado é o da gestão por resultados por meio da busca da qualidade total.

Essa lógica foi promovida por uma apologia dada ao mercado como organizador da vida social e fortaleceu-se na defesa da privatização de empresas públicas e de políticas públicas orientadas para o mercado, baseando-se, pois, na busca do trinômio da competência, da eficiência e da eficácia para a obtenção de melhores resultados, buscando assim, gerar menos ônus aos cofres públicos.

Por certo, ao longo dos anos de 1990, na reforma da educação, particularmente da educação superior no Brasil, delineou-se o desenvolvimento do modelo gerencial de gestão da educação, subordinado à lógica empresarial e ao mercado competitivo, frutos da influência das políticas neoliberais recorrentes nesse período, que respondiam às novas demandas do capital, eliminando com isso as tendências dos modelos de gestão considerados antigos e que não respondiam mais aos anseios da gestão e do capital moderno.

\section{Notas}

1. Luiz Carlos Bresser-Pereira é economista e cientista social na Fundação Getúlio Vargas. Em abril de 1987, em meio à crise provocada pelo fracasso do Plano Cruzado, tornou-se Ministro da Fazenda do governo Sarney. Em 1995, depois de ocupar a tesouraria da campanha de Fernando Henrique Cardoso para a presidência da república, assumiu o Ministério da Administração Federal e Reforma do Estado - Mare -, no qual comandou a Reforma da Gestão Pública de 1995. No segundo mandato, foi, durante os primeiros seis meses, Ministro da Ciência e Tecnologia.

2. Prebendas é um termo utilizado por Max Weber ao analisar os tipos de dominações. Significa uma categoria da apropriação de oportunidades de aquisição e de cargos, ou ainda, receitas apropriadas de emolumentos provenientes das reservas de bens e dinheiro do senhor (WEBER, 1991, p. 154).

3. O Contrato de gestão, segundo o Artigo $5^{\circ}$ da Lei no 9.637, de 15 de maio de 1998, refere-se ao instrumento firmado entre o Poder Público e a entidade qualificada como organização social, com vistas à formação de parceria entre as partes para o fomento e a execução de atividades relativas às áreas relacionadas ao ensino, à pesquisa científica, ao desenvolvimento tecnológico, à proteção e preservação do meio ambiente, à cultura e à saúde.

4. O PNP seria criado mediante Decreto pelo Poder Executivo e teria o objetivo de estabelecer diretrizes e critérios para a qualificação das organizaçôes sociais, o que seria garantido por meio da Lei no. 9.637, de 15 de maio de 1998. 


\section{Referências}

ANDERSON, Perry. Balanço do neoliberalismo. In: SADER, Emir; GENTILI, Pablo (Orgs.). Pós-neoliberalismo: as políticas sociais e o Estado democrático. São Paulo: Paz e Terra, 1995, p. 9-23. ASSOCIAÇÃO BRASILEIRA DE NORMAS TÉCNICAS, NBR 10520: referências bibliográficas. 4. ed. Rio de Janeiro: ABNT, 2002.

BANCO MUNDIAL. La Eseñanza Superior: las lecciones derivadas de la experiencia. Washington: World Bank, 1995.

BRASIL. Decreto no 2.207/97. Regulamentação do Sistema Federal de Ensino, 1997.

. Decreto no 2.306/97. Regulamentação do Sistema Federal de Ensino. 1997.

. Plano Diretor da Reforma do Aparelho do Estado. Câmara da Reforma do Estado. Brasília: Mare, 1995.

. Constituição da República Federativa do Brasil (1998). Brasília: Senado Federal, 1988.

Lei $n^{\circ}$ 9.394, de 20 de dezembro de 1996. Estabelece as diretrizes e bases da educação nacional - LDB. Brasília: Diário Oficial da União, 23 dez. 1996.

BRESSER-PEREIRA, Luiz Carlos. A reforma do Estado nos anos 90: lógica e mecanismos de controle. Cadernos Mare. vol. 1, 58 p. Brasília, 1997.

. Uma resposta estratégica aos desafios do capitalismo global e da democracia. In: Balanço da Reforma do Estado no Brasil: A Nova Gestão Pública. Brasília: MP/Seges, 2002. Disponível em: <http://www.bresserpereira.org.br/view.asp?.cod=1941>. Acesso em: 4 abr. 2006.

.; SPINK, Peter (Orgs.). Reforma do Estado e da administração pública gerencial. São Paulo: Fundação Getúlio Vargas, 2001.

CARDOSO, Fernando Henrique. Reforma do Estado. In: BRESSER-PEREIRA, Luiz Carlos; SPINK, Peter. Reforma do Estado e da administração pública gerencial. São Paulo: Fundação Getúlio Vargas, 2001, p. 15-19.

CHAUÍ, Marilena. A universidade em ruínas. In: TRINDADE, Hélgio. (Org.). Universidade em ruínas na república dos professores. Petrópolis: Vozes / Rio Grande do Sul: Cipedes, 1999. p. 211-222.

CURY, Carlos Roberto Jamil. A educação superior na nova Lei de Diretrizes e Bases da Educação Nacional: uma nova reforma? In: CATANI, Afrânio Mendes (Org.). Novas perspectivas nas políticas de educação superior na América Latina no limiar do século XXI. Campinas: Autores Associados, 1998. p. 75-81.

GENTILI, Pablo. (Org.). Universidades na penumbra: neoliberalismo e reestruturação universitária. São Paulo: Cortez, 2001.

A falsificação do consenso - Simulacro e imposição na reforma educacional do neoliberalismo. Petrópolis: Vozes, 1998.

LIMA, Licínio C. O paradigma da educação contábil: políticas educativas e perspectivas gerencialistas no ensino superior em Portugal. In: SGUISSARDI, Valdemar; SILVA JÚNIOR, João dos Reis da (Orgs.). Políticas públicas para a educação superior. Piracicaba: Edunimep, 1997. p. 23-62. 
LORDÊLO, José Albertino Carvalho. Publicização da Gestão Escolar: Descentralização Radical, Privatização ou Desresponsabilização do Estado? Revista Brasileira de Política e Administração. Porto Alegre: Anpae, v. 17, n. 2, p. 171-186, jul./dez. 2001.

MANCEBO, Deise. Políticas para a educação superior e cultura universitária: o exercício da solidão no ideário neoliberal. 1998. Disponível em: <http://www2.uerj.br/\%7Eanped11/21/ MANCEBO.htm>. Acesso em: 15 maio 2006.

OLIVEIRA, João Ferreira de; CATANI, Afrânio Mendes. Educação Superior no Brasil - Reestruturação e metamorfose das universidades públicas. Petrópolis: Vozes, Coleções Universit@s, 2002.

.; _____. A reestruturação da educação superior no debate internacional: a padronização das políticas de diversificação e diferenciação. Universidade e Sociedade. Brasília: Andes, v. 10, n. 21, p. 92-101, jan./abr. 2000.

PIMENTA, Carlos César. A reforma gerencial do Estado brasileiro no contexto das grandes tendências mundiais. Revista de Administração Pública, Rio de Janeiro, v. 32, n. 5, p. 173-1999, set./out. 1998.

SHIROMA, Eneida Oto; MORAES, Maria Célia M. de; EVANGELISTA, Olinda. Política educacional. 3. ed. Rio de Janeiro: DP\&A, 2004.

SILVA JÚNIOR, João dos Reis da. Reforma do Estado e da Educação no Brasil de FHC. São Paulo: Xamã, 2002.

.; SGUISSARDI, Valdemar (Orgs.). Novas faces da educação superior no Brasil: reforma do Estado e mudança na produção. Bragança Paulista, SP: EDUSF, 1999. 


\section{Restructurings in the Brazilian public administration and the unfoldings in higher education} Abstract

This article brings forth elements for analysis and discussion about the restructuring process of the Brazilian public administration with respect to the reformist movement launched in the 1990's, aiming to locate and understand the unfolding of those transformations in higher education. The reflection begins on the basis of the understanding of a set of notes and reflections regarding the enterprise of reforms known as "managerialist", so as to set it in the social, economical and political context which permeated it. Their proposals and objectives are emphasized, based on the arguments presented by several official documents and the perspectives of their idealizers. Finally, it proposes a reflection of this reformist process and its implications for a new model of administration, also required for higher education.

Keywords: Administrative reform. Higher Education. Higher Education Reform.

\section{Restructurations dans l'administration publique brésilienne et ses déroulements dans l'enseignement supérieur \\ Résumé}

Cet article présente des éléments pour l'analyse et discussion au sujet du processus de restructuration de l'administration publique brésilienne face au mouvement réformiste initié dans les années 90 du siècle $X X$, dans l'objectif de situer et comprendre les découlements de ces transformations dans l'enseignement supérieur. La réflexion commence à partir de la compréhension d'un ensemble de notes et réflexions sur l'initiative de réformes connues comme gérentialistes, de façon à les situer dans le contexte social, économique et politique qui l'a imprégné. L'on ressort ses propositions et ses objectifs orienteurs en se basant sur les arguments présentés par divers documents officiels et les perspectives de ses idéalisateurs. Enfin, l'on propose une réflexion de ce processus réformiste et ses implications pour un nouveau modèle de gestion, aussi requise par l'enseignement supérieur.

Mots clefs: Réforme universitaire. Enseignement supérieur. Réforme de l'éducation.

\section{Reestructuraciones en la administración pública brasileña y los desdoblamientos en la educación superior Resumen}

Ese artículo presenta elementos para análisis y discusión acerca del proceso de reestructuración de la administración pública brasileña frente al movimiento reformista desencadenado en los años 90 del siglo $X X$, objectivando situar y comprender los desdoblamientos de esas transformaciones en la educación superior. La reflexión inicia a partir de la comprensión de un conjunto de apuntes y reflexiones acerca de la empresa de reformas conocido por gerencialista, de modo a situarlo en el contexto social, económico y político que lo permeó. Se resalta sus propuestas y sus objectivos norteadores basándose en los argumentos presentados por diversos documentos oficiales y perspectivas de sus idealizadores $y$, por fin, se propone una reflexión de ese proceso reformista y sus implicaciones para un nuevo modelo de gestión, también requerido para la educación superior.

Palabras-clave: Reforma administrativa. Educación superior. Reforma en la educación.

Recebida I ${ }^{\mathbf{a}}$ versão em: |8.03.2008

Aceita $2^{\mathrm{a}}$ versão em: 16.10.2008 